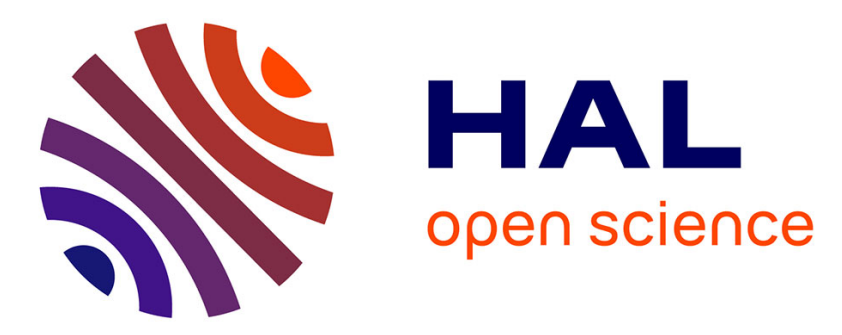

\title{
Mechanical behavior of periodical microstructure induced by friction stir welding on $\mathrm{Al}-\mathrm{Cu}-\mathrm{Li} 2050$ alloy
}

Matthieu Dhondt, Isabelle Aubert, Nicolas Saintier, Jean-Marc Olive

\section{To cite this version:}

Matthieu Dhondt, Isabelle Aubert, Nicolas Saintier, Jean-Marc Olive. Mechanical behavior of periodical microstructure induced by friction stir welding on $\mathrm{Al}-\mathrm{Cu}-\mathrm{Li} 2050$ alloy. Materials Science and Engineering: A, 2015, 644, pp.69-75. 10.1016/j.msea.2015.05.072 . hal-02334039

\section{HAL Id: hal-02334039 \\ https://hal.science/hal-02334039}

Submitted on 25 Oct 2019

HAL is a multi-disciplinary open access archive for the deposit and dissemination of scientific research documents, whether they are published or not. The documents may come from teaching and research institutions in France or abroad, or from public or private research centers.
L'archive ouverte pluridisciplinaire HAL, est destinée au dépôt et à la diffusion de documents scientifiques de niveau recherche, publiés ou non, émanant des établissements d'enseignement et de recherche français ou étrangers, des laboratoires publics ou privés. 


\title{
Mechanical behavior of periodical microstructure induced by friction stir welding on Al-Cu-Li 2050 alloy
}

\author{
Matthieu Dhondt ${ }^{\mathrm{a}, \mathrm{b}, 1}$, Isabelle Aubert $^{\mathrm{a}, *}$, Nicolas Saintier ${ }^{\mathrm{b}}$, Jean-Marc Olive ${ }^{\mathrm{c}}$ \\ a Université de Bordeaux, I2M, UMR 5295, 351 cours de la Libération, 33405 Talence Cedex, France \\ ${ }^{\mathrm{b}}$ Arts et Métiers ParisTech (centre de Bordeaux-Talence), I2M, UMR 5295, Esplanade des Arts et Métiers, 33405 Talence Cedex, France \\ ' CNRS, I2M, UMR 5295, 351 cours de la Libération, 33405 Talence Cedex, France
}

Keywords:

Aluminum alloy

Friction stir welding

Mechanical behavior

Microstructure

Crystal plasticity

Simulation

\begin{abstract}
A B S T R A C T
Mechanical behavior analysis of the friction stir weld nugget of an aluminum alloy 2050 reveals a major role of the microstructure which varies with the distance to the weld surface. Three types of microstructure heterogeneities are considered namely grain size, precipitation state and textured bands. The grain size and the T1 precipitates density decrease with the distance from the weld surface. The density of T1 precipitates has a first order effect on micro-hardness variations and makes the Hall-Petch rule not valid in this case. Tensile tests combined with strain field identification done by digital image correlation measurements demonstrate the good correlation between textured bands and strain field heterogeneities. Crystal plasticity simulations by finite element method well account for the macroscopic mechanical behavior as well as strain field in textured bands.
\end{abstract}

\section{Introduction}

Friction stir welding (FSW) of aluminum alloys is becoming a mature and robust process and has extended the use of welding in particular for 2xxx and 7xxx alloys in aeronautic industry. In addition, FSW is very efficient where it is necessary to join different aluminum alloys. Applied for example on lightweight aluminum lithium alloys [1], this welding technique could significantly reduce the weight of aerospace structures by limiting the use of rivets, fasteners and overlapping areas. Exhaustive review on the principles of FSW and on the properties of welds, as well on potential industrial applications in shipbuilding, offshore, railways, automotive and so on, was proposed in [2,3]. Friction stir-welded joints consist of three zones involving specific microstructures, namely heat affected zone (HAZ), thermo-mechanically affected zone (TMAZ) and weld nugget (WN). The weld nugget is the dynamically recrystallized region of the TMAZ resulting in a fine equiaxed microstructure [4]. Key microstructural parameters such as precipitation state influencing local hardness within the weld joints were clearly identified on AA2199 and AA2024 [5,6]. A big effort in modeling the in-process temperature evolution, the

\footnotetext{
* Corresponding author. Fax +33540006964.

E-mail address: i.aubert@i2m.u-bordeaux1.fr (I. Aubert).

${ }^{1}$ Now at Laboratoire Brestois de Mécanique et des systèmes LBMS EA 4325, ENSTA-Bretagne, 2 rue François Verny, 29806 Brest Cedex 9, France.
}

microstructure evolution, the strain hardening and some damage processes devoted to the FSW of 6xxx series aluminum alloys has resulted in an integrated modeling framework [7]. Different modes of degradation of the weld joints were studied. The effect of residual stress as well as the microstructure on the fatigue behavior was approached in $[8,9]$. The corrosion behavior was recently analyzed by accounting for the reactivity of the different domains of the joint $[10,11]$. The galvanic coupling level was associated to the local corrosion potential, the microstructure and the hardness. The galvanic coupling was also shown to be affected by the heterogeneous stress field induced by external mechanical loading. More specifically on the welding of 2050 aluminum alloys, postwelding heat treatment significantly changes the corrosion behavior of the base metal leading to an inversion in the galvanic coupling [12]. The intrinsic properties of the weld nugget were less studied. In this region, metallographic observations reveal commonly elliptical periodical features often termed "onion rings". These onion-rings were assimilated to bands having either different precipitation states [13], modified average grain size [14], or a variation of crystallographic texture [15]. On 2050 alloy, galvanic corrosion was identified between these bands [16]. The other important effect of the onion rings wasobserved on 2050 weld nugget under stress corrosion cracking condition [17]. During slow strain rate tests (uniaxial loading in the $L$ direction at a strain rate of $10^{-6} \mathrm{~s}^{-1}$ in $1.0 \mathrm{M} \mathrm{NaCl}$ aerated solution at room temperature), intergranular stress corrosion cracking occurs along the $T$ direction 
on the $L-T$ surface of the flat tensile specimens. Electron Back Scattered Diffraction (EBSD) analysis of the surroundings of the cracks showed that the long cracks initiate and propagate along the interface of textured bands corresponding to onion rings. The question of the effect of the local variation of the texture on the stress/strain field heterogeneity was proposed as one of the key issues to be addressed. Experiments combined with numerical approaches try to provide a description of stress/strain field heterogeneity in 2050 weld nugget.

\section{Material and methods}

The material used in this work is a weld nugget obtained by friction stir welding of two $15 \mathrm{~mm}$ thick sheets of AA2050 T3 (solutionizing, quenching and stretching), submitted to a postwelding heat treatment at $155^{\circ} \mathrm{C}$ during $30 \mathrm{~h}$. Nugget microstructure heterogeneities in the depth were analyzed from samples machined in section perpendicular to the welding direction, mechanically polished up to $1 / 4 \mu \mathrm{m}$ using OP-S solution and etched during $2 \mathrm{~min}$ in a solution of $40 \mathrm{ml}$ of tetrafluoroboric acid $\left(\mathrm{HBF}_{4}\right)$ and $760 \mathrm{ml}$ of distilled water with a current density of $0.2 \mathrm{~A} \mathrm{~cm}^{-2}$. Then, the samples were observed using an optic microscope (Olympus PMG3). The T1 precipitation was quantified by the SIMaP laboratory in the European synchrotron radiation facility (ESRF) in Grenoble by Small Angle X-ray Scattering (SAXS) measurements [18]. Nugget microstructure in the welding direction is characterized using tensile specimens machined in the nugget zone, by series of 6 specimens in the depth (see Fig. 1). All specimens were mechanically polished up to $1 / 4 \mu \mathrm{m}$ using OP-S solution. Electron Back Scattered Diffraction (EBSD) maps (EDAX's high sensitivity EBSD camera) were performed along the gauge length of the tensile specimens, before testing. The size of the maps is about $1500 \mu \mathrm{m} \times 400 \mu \mathrm{m}$ with a step of $2 \mu \mathrm{m}$.

Mechanical heterogeneities were highlighted by Vickers microhardness measurements and tensile tests. Vickers microhardness maps $\mathrm{Hv}_{0.5}$ were performed in the section perpendicular to the welding direction of the weld nugget with a step of $0.5 \mathrm{~mm}$, using a Duramin A300D Struers microhardness tester. After EBSD measurements, tensile tests were conducted at a strain rate of $\dot{\epsilon}=5 \cdot 10^{-5} \mathrm{~s}^{-1}$ on a $5 \mathrm{kN}$ Deben Microtest tensile stage. The specimens were instrumented with gauges to measure strain between 0 and $2 \%$. For more than $2 \%$, strain was determined using a LVDT displacement measurements. Local strain fields were obtained using Digital Image Correlation (DIC) method and the software Correli $^{\mathrm{Q} 4}$. Before tensile tests, the specimens were electrolytically etched in a $\mathrm{HBF}_{4}$ solution, allowing creation of a texture favorable for DIC measurements. A digital microscope KEYENCE VHX-1000E was used as an in situ surface observation technique taking one image every $15 \mathrm{~s}$ during the tensile test (for a $\Delta \epsilon=7.5 \cdot 10^{-4}$ ). To obtain displacement fields of the deformed image with respect to a reference image, the region of interest of $1600 \mathrm{px} \times 1200 \mathrm{px}$ ( 1 pixel $=1 \mu \mathrm{m})$, containing the EBSD map zone, was partitioned into sub-images, called zone of interest (ZOI), of $32 \mu \mathrm{m} \times 32 \mu \mathrm{m}$. The correlation principle is used to compare the ZOI in both images, allowing the calculation of the mean value of the local strain on about 10 grains.

\section{Modeling}

In order to understand the origin of the strain fields heterogeneities, a finite element model was built using the code $\mathrm{ZeBu}$ LoN [19]. The details of the geometry and mesh are given in Section 4.3. The mechanical behavior of the nugget was described by a crystal elasto-plasticity model taking into account 12 slip systems for the FCC crystal, as proposed by Cailletaud et al. [20]. Anisotropic elasticity was used to described the elastic behavior. For the nugget microstructure, cubic elasticity coefficients of pure aluminum were considered $\left(C_{1111}=108 \mathrm{GPa}, \quad C_{1122}=28.3 \mathrm{GPa}\right.$ $C_{1212}=62 \mathrm{GPa}$ ). At the grain scale, inelastic deformation mainly results in slip on the possible slip systems of the crystal. The resolved shear stress $\tau_{s}$ on each slip system $s$ is given by the following equation:

$$
\tau_{s}=\underline{\underline{\sigma}}: \underline{\underline{m}}^{s} \quad \text { with } \underline{\underline{m}}^{s}=\frac{1}{2}\left(\vec{n}^{s} \otimes \vec{l}^{s}+\vec{l}^{s} \otimes \vec{n}^{s}\right)
$$

where $\vec{n}^{s}$ and $\vec{l}^{s}$ are the slip plane normal and the slip plane

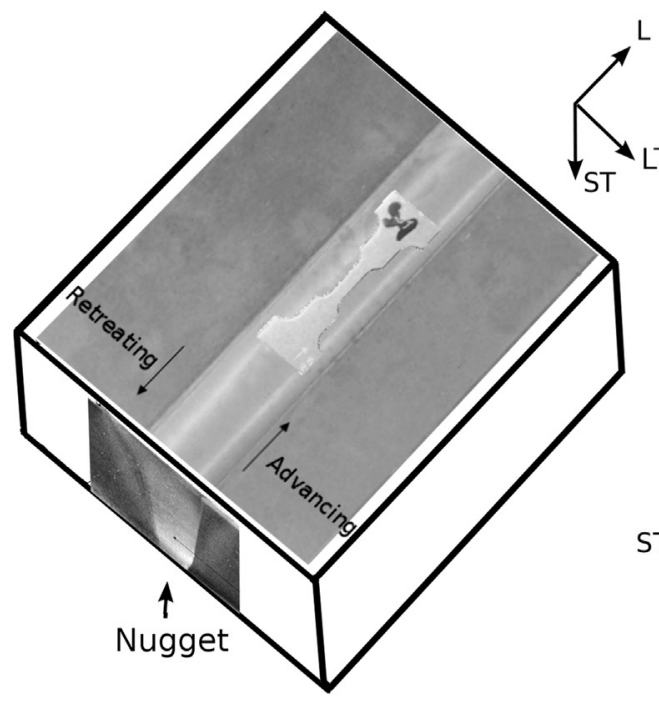

(1)
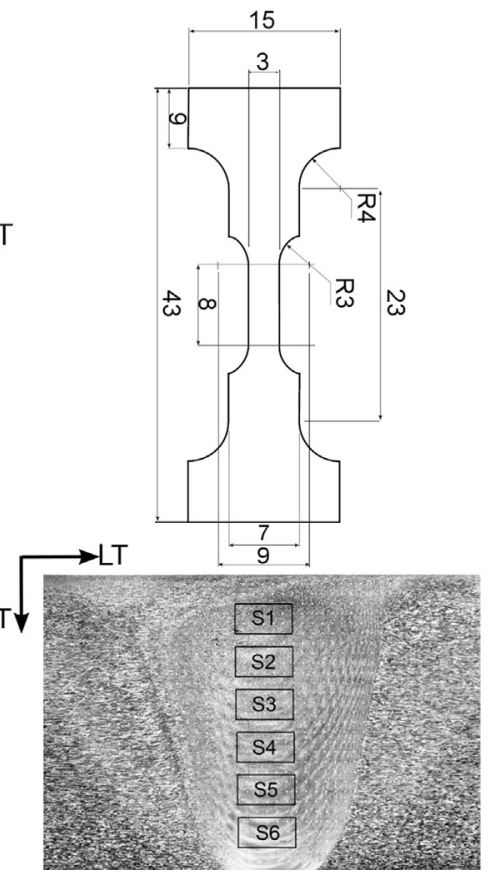

Fig. 1. Location of the tensile specimen sampling in the $L-L T$ and $L T-S T$ plane of the weld. Tensile specimen dimensions in millimeter (thickness: 1.5 mm). 
direction, respectively. Cailletaud et al. [20] proposed a phenomenological formulation for the flow rule and the hardening law, based on thermodynamics of irreversible processes. The plastic flow rate $\dot{\gamma}_{s}$ on the slip system $s$ is given by the following equation:

$\dot{\gamma}_{s}=\left\langle\frac{\left|\tau_{s}\right|-\tau_{s}^{c}}{K}\right\rangle^{n} \operatorname{sign}\left(\tau_{s}\right)$

where $K$ and $n$ characterize the material rate sensitivity and $\tau_{s}^{\mathrm{c}}$ the resolved shear stress threshold. In this work, only monotonic loading was considered. Consequently, the evolution of the critical resolved shear stress could be described by a nonlinear isotropic hardening law:

$\tau_{s}^{\mathrm{c}}=\tau_{0}^{\mathrm{c}}+Q \sum_{r} h_{r s}\left(1-e^{-b \nu_{r}}\right) \quad$ with $\nu_{r}=\int_{0}^{t}\left|\gamma^{r}\right| \mathrm{d} t$

The parameters $\tau_{0}, Q$ and $b$ were optimized by fitting the results obtained from the finite element calculations and the experimental tensile test curve. To do that, a part of $800 \times 200 \times 6 \mu \mathrm{m}^{3}$ of the gauge length was modeled by a rectangular aggregate regularly meshed with cubic elements of $6 \times 6 \times 6 \mu \mathrm{m}^{3}$. The crystal orientations were attributed to the Gauss point according to the EBSD map. The obtained crystal plasticity model coefficients are the following: $K=50 \mathrm{MPa} \mathrm{s}^{1 / n}$, $n=25, \tau_{0}{ }^{c}=66 \mathrm{MPa}, Q=50.0, b=40$. Self-hardening and latent hardening due to interactions between slip systems are introduced by the matrix $h_{r s}$. In this case, the interaction matrix was simplified by using Taylor hardening hypothesis $\left(h_{r s}=1\right)$.

\section{Results}

\subsection{Microstructural heterogeneities}

\subsubsection{Microstructural heterogeneities in the LT-ST plane}

After mechanical polishing and etching, some characteristics of the microstructure are revealed and are visible by optic microscopy (Fig. 2a). At the scale of the weld joint, the cross sections of the "onion rings" have pseudo-elliptic shapes and are arranged periodically. In the central ST direction of the weld joint, these onion rings are periodically spaced of about $500 \mu \mathrm{m}$. The analysis at lower scale shows that the microstructure is composed of equiaxed grains with sizes decreasing from $17 \mu \mathrm{m}$ at the top of the weld down to $4 \mu \mathrm{m}$ at the bottom of the weld (yellow curve in Fig. 2a). These data are consistent with those reported in the literature $[4,21]$. By applying SAXS techniques (Small Angle X-Ray Scattering) at the ESRF (European Synchrotron Radiation Facility) on the weld joint of the same material, the density of T1 hardening precipitates was estimated to decrease from the top to the bottom of the nugget [18].

\subsubsection{Microstructural heterogeneities in the L-LT plane}

EBSD on the $L-L T$ plane and in the middle of the weld nugget (Fig. 3) shows clearly that the onion ring sections correspond to domains of material having different textures. The periodicity of the texture bands corresponds to the one observed on the $L T-S T$ section. Two types of periodical bands are distinguished and are characterized by an orientation distribution function (ODF) in the plane $\phi_{2}=45^{\circ}$. Type A bands contain the orientation (112)[110] of the alpha fiber and the orientation (110)[110]. Type B bands contain directions (111)[110] and (111)[011] of the gamma fiber. These results are consistent with the fact that the texture is one of the major microstructural features of the different bands in the onion rings structure [15].
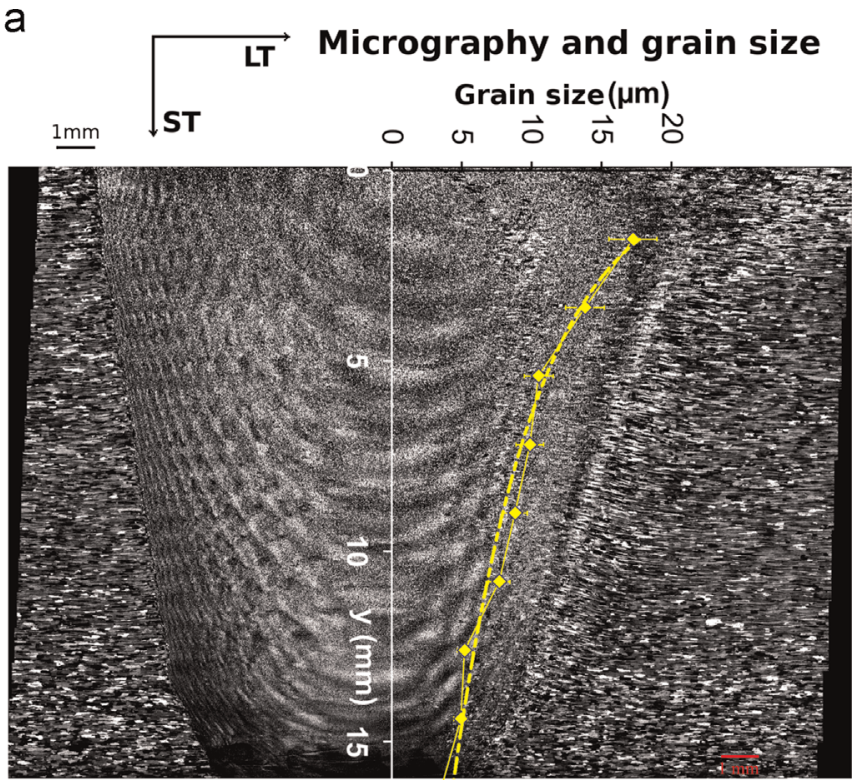

b SAXS measurements

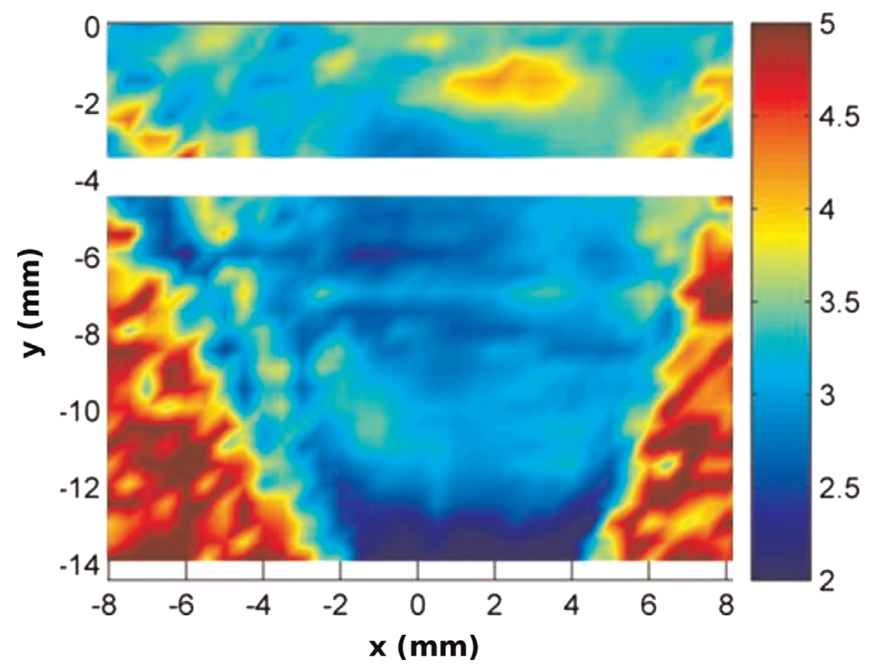

Fig. 2. (a) Grain size and (b) T1 precipitates density variations in the weld nugget [18]. (For interpretation of the references to color in this figure caption, the reader is referred to the web version of this paper.)

\subsection{Heterogeneities of mechanical behavior}

4.2.1. Mechanical properties along $L$ direction according to the position in the weld nugget

To analyze the mechanical behavior of the weld nugget, uniaxial tension tests were done at the strain rate of $510^{-5} \mathrm{~s}^{-1}$ on specimens machined at different distances from the weld surface (specimen S1-S6). Each test was reproduced three times in the same conditions. The gauge length of the tensile specimens is $8 \mathrm{~mm}$ and the cross section area is about $4.5 \mathrm{~mm}^{2}$. In the gauge length, the specimen contains about 30 textured bands and there are about $45 \cdot 10^{3}$ grains in the cross section. The characteristic mechanical data (Young modulus $E$ (GPa), the yield strength $R_{p 0.2}$ (MPa), the fracture stress $R_{m}(\mathrm{MPa})$ and the strain at rupture $\mathrm{A}(\%)$ ) given in Fig. 4 are then considered to be representative of the macroscopic behavior of the weld nugget in the $L$ direction at the different sampling levels. No significant variation is observed for $E$, $R_{p 0.2}$ and $R_{m}$. The average values of $E, R_{p 0.2}, R_{m}$ are $70 \mathrm{GPa}, 310 \mathrm{MPa}$ and $410 \mathrm{MPa}$, respectively. Considering the decrease of grain size 


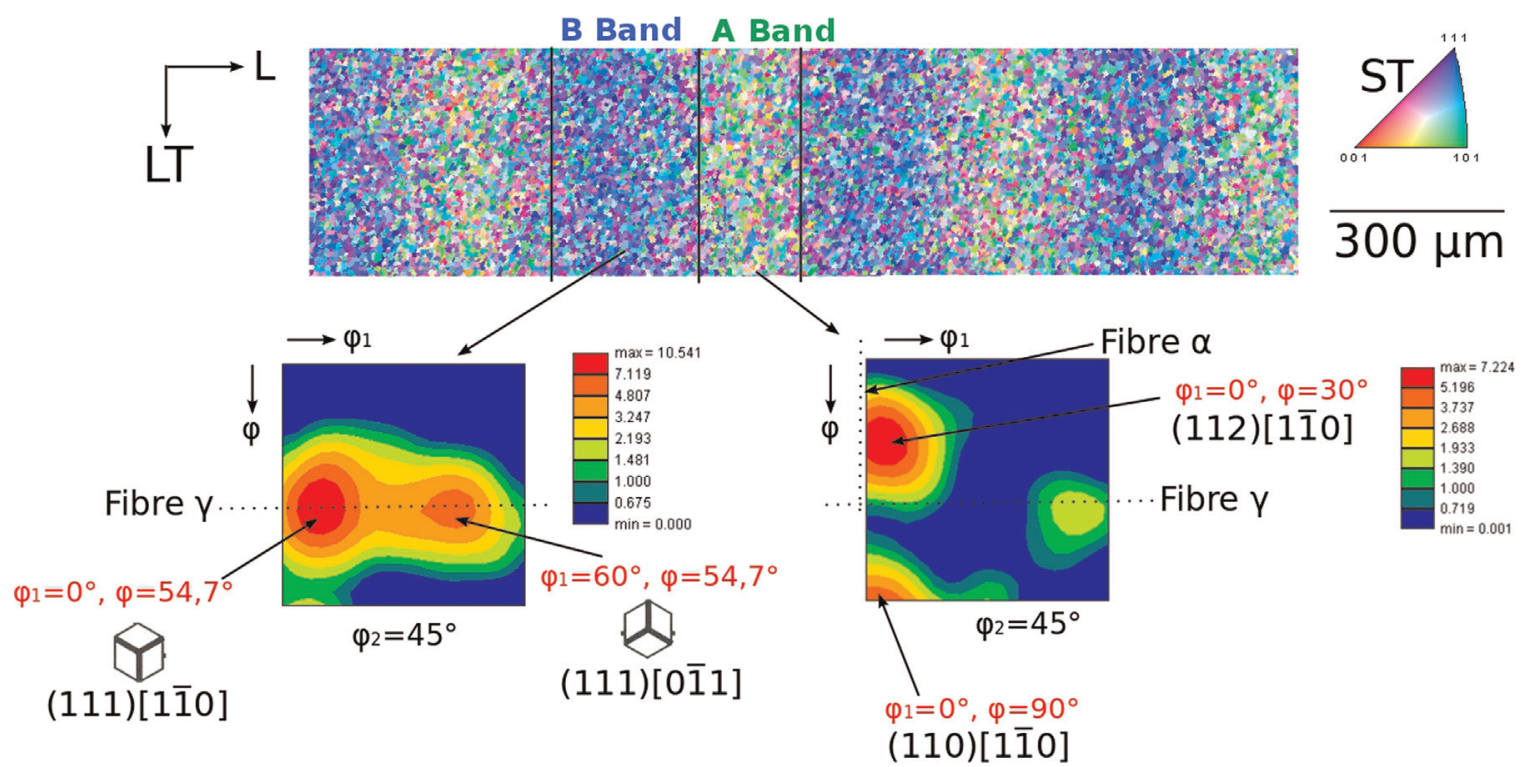

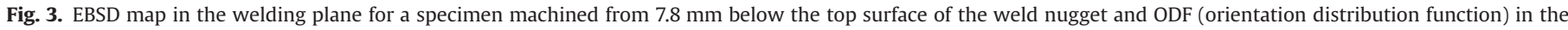
plane $\phi_{2}=45^{\circ}$ for each texture band.

from $17 \mu \mathrm{m}$ to $4 \mu \mathrm{m}$ and the Hall-Petch rule saying that $R_{e}$ scales $d^{-1 / 2}, R_{p 0.2}$ should increase by about a factor 2 from S1 to S6. The fact that $R_{p 0.2}$ is constant means that the grain size effect is of the second order compared to the effect of the T1 density. This assumption is confirmed by the evolution of the hardness. The Vickers microhardness decreases from $155 \mathrm{Hv}$ to $125 \mathrm{Hv}$ though the grain size decreases from $17 \mu \mathrm{m}$ to $4 \mu \mathrm{m}$. The opposite effect could be expected by applying the Hall-Petch type scaling to $d^{-1 / 2}$ on Hv. This scaling is usually operant when $R_{e}$ or $R_{m}$ are proportional to $\mathrm{Hv}$ by a factor $2-4$. $R_{m}$ is about 3 times the average microhardness measured on the specimens S1-S6 but there is not a decrease of $R_{m}$ with the microhardness and then no proportionality. The mechanical behavior of the nugget does not follow expected typical rules. The gradients of $\mathrm{T} 1$ density and grain size as well as the presence of textured bands make the mechanical behavior unusual. The specimens after failure are shown in Fig. 5. Though the fracture mode is ductile in all the cases, the fracture morphology is different depending on the sampling level in the nugget. On specimens S1-S3, the fracture occurs along a plane called $P_{1}$ making an angle of about $45^{\circ}$ with the tensile direction and the intersection with the $L-L T$ plane is parallel to the $L T$ direction. A change of orientation of the fracture surface occurs progressively for the specimens S4-S6. Fracture occurs not only along the plane $P_{1}$ but also along directions making an angle of about $45^{\circ}$ on the $L-L T$ plane. For the specimen $S 6$, the intersection between the fracture surface and the $L-L T$ plane is made of segments at $45^{\circ}$ of the tensile direction. The reasons of these changes in the fracture morphology are not well understood. It can be only assumed that the T1 distribution and/or density may affect the shear orientation.

\subsubsection{Local strain heterogeneities in the L-LT plane}

To quantify textured band-induced heterogeneity level of the strain field, analysis by DIC was done during all tensile tests. An example of axial strain field $\epsilon_{11}$ is shown in Fig. 7 (specimen S4 at $7 \%$ deformation). The first observation is that the average axial deformation is always higher in the type A than in type B bands. It is to be noticed that, because of the plastic deformation of the
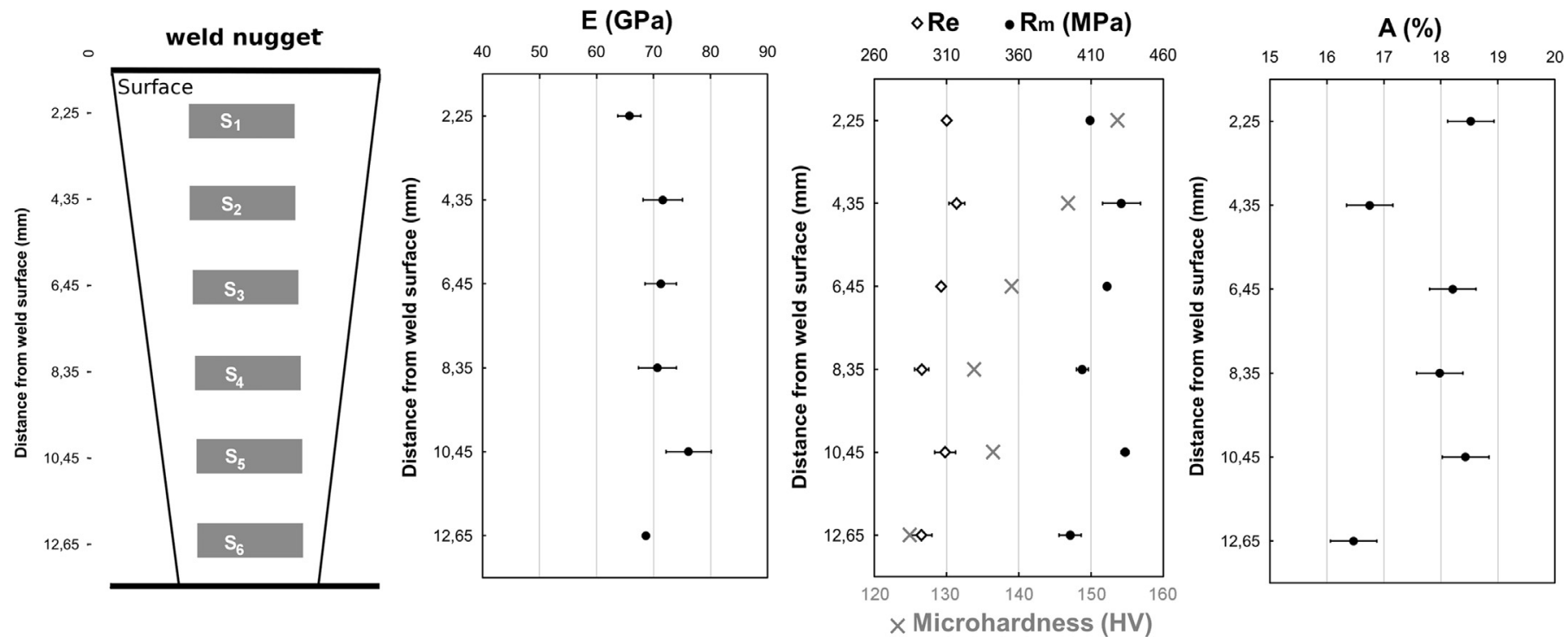

Fig. 4. Mechanical properties as a function of the distance from weld surface. 


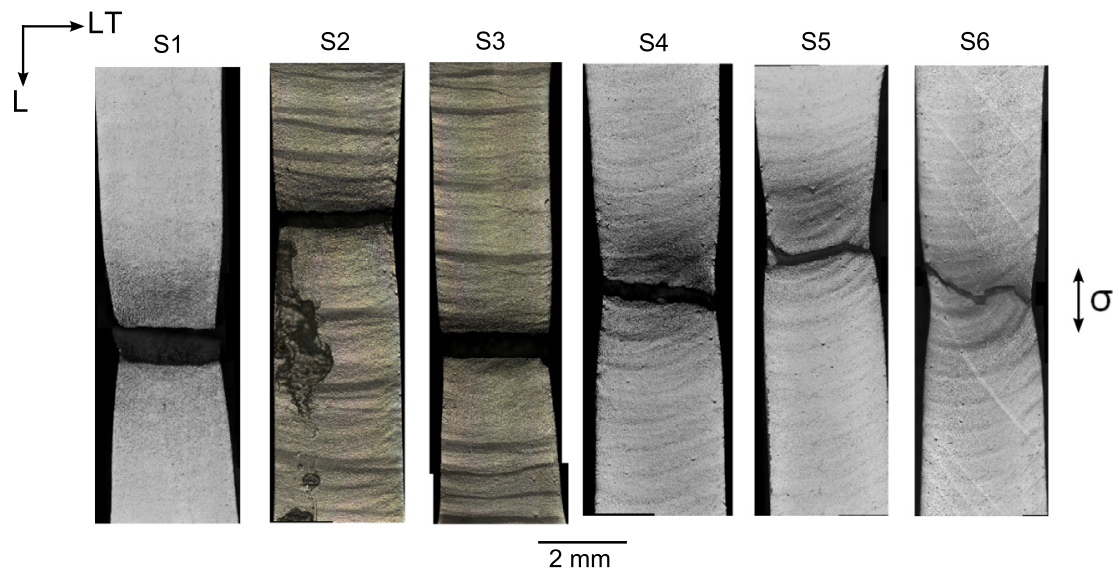

Fig. 5. Optic images of specimens after tensile test up to failure.

Table 1

Average values of local strain $\epsilon_{11}(\%)$ in the tensile direction, for both types of band for the specimens S2-S6 at different levels of macroscopic strain.

\begin{tabular}{|c|c|c|c|c|c|c|}
\hline$\epsilon_{\text {macro }}(\%)$ & $\epsilon_{\text {Band }}$ & S2 & S3 & S4 & S5 & S6 \\
\hline \multirow[t]{3}{*}{1} & $\epsilon_{\mathrm{A}}-\epsilon_{\text {macro }}$ & 0.22 & 0.17 & 0.01 & 0.02 & 0.01 \\
\hline & $\epsilon_{\mathrm{B}}-\epsilon_{\text {macro }}$ & -0.04 & -0.02 & 0 & -0.01 & -0.01 \\
\hline & $\epsilon_{\mathrm{A}}-\epsilon_{\mathrm{B}}$ & 0.26 & 0.19 & 0.01 & 0.03 & 0.02 \\
\hline \multirow[t]{3}{*}{3} & $\epsilon_{\mathrm{A}}-\epsilon_{\text {macro }}$ & 0.68 & 0.59 & 0.27 & 0.33 & 0.43 \\
\hline & $\epsilon_{\mathrm{B}}-\epsilon_{\text {macro }}$ & -0.25 & -0.16 & -0.25 & -0.21 & -0.42 \\
\hline & $\epsilon_{A}-\epsilon_{B}$ & 0.93 & 0.75 & 0.52 & 0.54 & 0.85 \\
\hline \multirow[t]{3}{*}{5} & $\epsilon_{\mathrm{A}}-\epsilon_{\text {macro }}$ & 1.13 & 1.05 & 0.55 & 0.65 & 0.83 \\
\hline & $\epsilon_{\mathrm{B}}-\epsilon_{\text {macro }}$ & -1.41 & -1.33 & -0.34 & -0.38 & -0.46 \\
\hline & $\epsilon_{A}-\epsilon_{B}$ & 2.54 & 2.38 & 0.89 & 1.03 & 1.29 \\
\hline \multirow[t]{3}{*}{7} & $\epsilon_{\mathrm{A}}-\epsilon_{\text {macro }}$ & 1.21 & 1.13 & 0.68 & 0.75 & 0.85 \\
\hline & $\epsilon_{\mathrm{B}}-\epsilon_{\text {macro }}$ & -1.69 & -1.58 & -0.42 & -0.55 & -0.62 \\
\hline & $\epsilon_{A}-\epsilon_{B}$ & 2.9 & 2.71 & 1.1 & 1.3 & 1.47 \\
\hline
\end{tabular}

specimen, the strain field heterogeneity measured by DIC does not correspond exactly to the bands shown on the EBSD map (undeformed configuration). The second observation is that the strain field is not homogeneous in each band. This former point is not commented in detail here since it concerns a scale of the polycrystal beyond the purpose of this study. The focus is done on the average strain fields in each texture band. The values of the differences between the axial average strain in a band and the macroscopic strain, for each band type, each specimen (except S1 since it does not contain textured bands) and for different levels of macroscopic strain are given in Table 1. It should be remind here that the average strain in a textured band is the average value on all values at each $\mathrm{ZOI}$ belonging to the band, each value at a $\mathrm{ZOI}$ being the average value of the strain of a group of 10 grains. From Table 1, it is remarkable that in all cases, the strain of type A bands is higher that the macroscopic strain and then higher than the strain in type B bands. The second remarkable point is that the gaps $\epsilon_{A}-\epsilon_{B}$ always decrease with the distance from the weld surface. In other words, the contrast in the strain field is higher close to the weld surface. This result may be crucial to account for in the context of possible damage resulting from the coupling between mechanical stress and corrosion process on the weld upper surface. The other characteristic point is that the gaps $\epsilon_{A}-\epsilon_{B}$ increases with the macroscopic strain in all the cases. It means that the hardening is higher in band B than in Band A on all the range of macroscopic strain 1-7\%. These results can be associated with some comments on the crystallographic features of the bands. From the EBSD analysis, Euler's angles of all the grains are obtained and the Schmid factor can be computed as $\cos \left(\theta_{s}\right) \cos \left(\chi_{s}\right)$, where $\theta_{s}$ is the angle between the tensile axis and the primary slip direction, and $\chi_{s}$ is the angle between the tensile axis and the normal of the primary slip plane. The average value of the Schmid factors of all the grains analyzed is 0.47 in type band $A$, and 0.45 in type band B. From the crystal orientation viewpoint and considering that slip is the deformation mechanism, the grains in type band A are deformed more than type band B by single slip. This is consistent with the results on the strain response of each band described previously. The crystallography data of the different bands were used to compute numerically the nugget by considering crystal plasticity model.

\subsection{Modeling of texture effect on mechanical fields heterogeneities}

A finite element model was built to quantify the effect of the onion rings on the local strain heterogeneities. A part of the gauge length $(2000 \times 750 \times 250 \mu \mathrm{m})$ was modeled by a rectangular aggregate regularly meshed, where each element represented a grain. The element size of $50 \mu \mathrm{m}$ was chosen for numerical reasons. Two distinct domains, oriented to $45^{\circ}$ in the depth, represent the two texture bands (A and B). For each texture band, a random selection of Euler's angles was chosen from the EBSD map and attributed to the Gauss points. The EBSD map constituted of 6000 grains was made on a S4 sample (see Fig. 6a). Boundary conditions are periodic displacements with an imposed stress of $430 \mathrm{MPa}$ in 

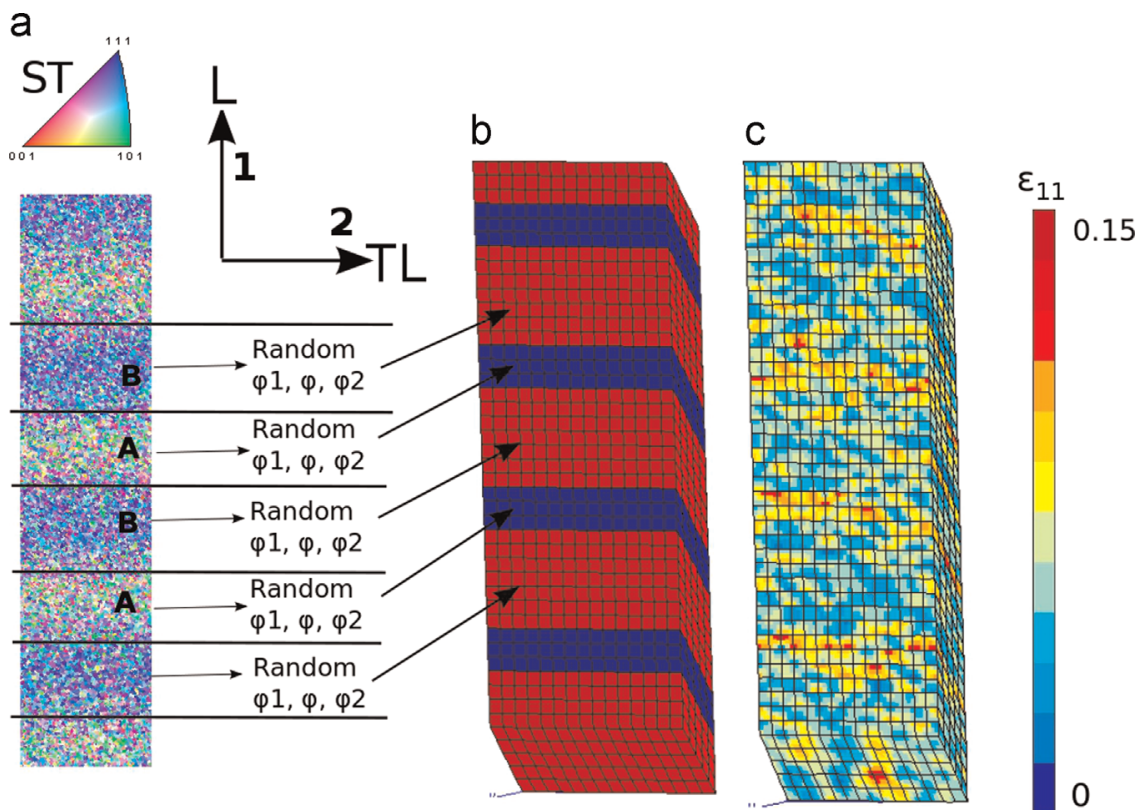

Fig. 6. (a) EBSD map of the gauge length, (b) mesh and domains used for fem computations, (c) axial strain map.

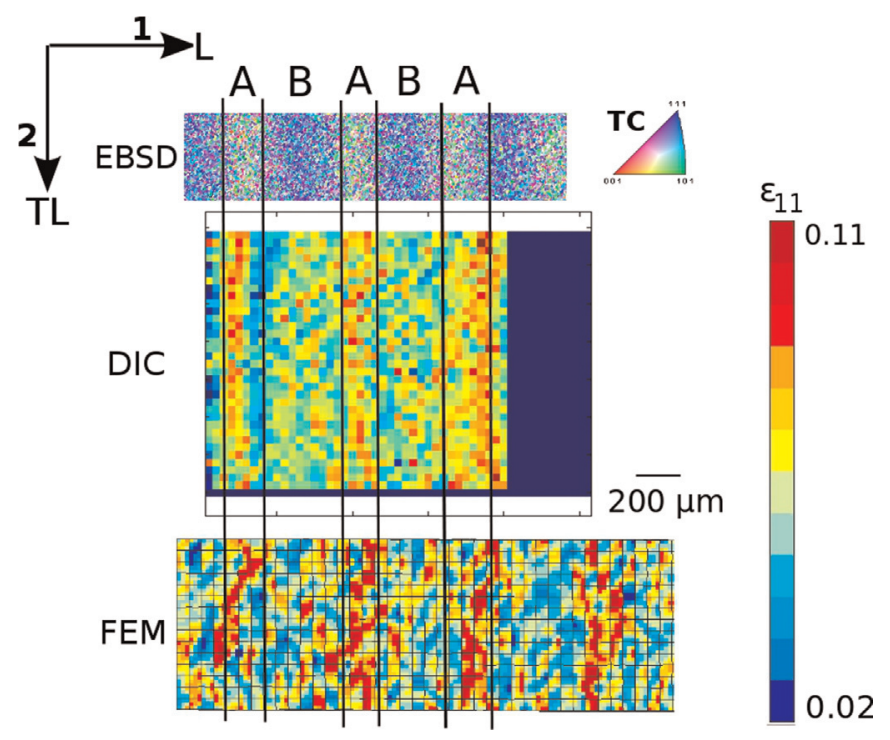

Fig. 7. Texture effect on local strain heterogeneities: results from DIC measurements and FEM computations after 7\% global plastic strain.

the 1 direction (Fig. 6).

Fig. 6 shows the axial strain map $\left(\epsilon_{11}\right)$ obtained by FEM computations. The domains corresponding to $\mathrm{A}$ bands are more strained than others, as expected by the Schmid factors calculations (see Section 4.1.2). A good agreement is observed between the strain heterogeneities highlighted by finite element calculation and by DIC measurements, and the texture bands (see Fig. 7). In each band heterogeneity of strain field is observed and computed. For the finite element model, each element represents one grain, and the results show the strain heterogeneities due to the variation of crystallographic orientations between different grains of a same texture band. While for DIC, the measured local strain corresponds to a mean value on about 10 grains (corresponding to the zone of interest size).

Fig. 8 shows the tensile tests curves obtained by DIC method (Fig. 8a), and by finite element method (Fig. 8b). On each graph, three curves are plotted:

- The red curve, called $\epsilon_{11}^{\text {total }}$, represents the average stress as a function of the average strain on the whole aggregate.

- The green curve, called $\epsilon_{11}^{A}$, represents the average stress as a function of the average strain on the A bands.

- The blue curve, called $\epsilon_{11}^{B}$, represents the average stress as a function of the average strain on the $B$ bands.

The ends of the tensile curves were drawn in Fig. 8c. DIC curves in dashed line and FEM ones in plain line are almost superimposed. As texture bands cross the entire width of the sample, the specimen can be assumed as a Reuss problem, where the sample and both texture bands are submitted to the same stress. We can note that, for DIC curves and FEM curves the inequality $\epsilon_{11}^{A} \geq \epsilon_{11}^{\text {total }} \geq \epsilon_{11}^{B}$ is clearly established whatever the macroscopic stress. For a macroscopic stress value of $430 \mathrm{MPa}$, the absolute variation between $\epsilon_{11}^{A}$ and $\epsilon_{11}^{\text {total }}$ is about $1 \%$ and the absolute variation between $\epsilon_{11}^{\text {total }}$ and $\epsilon_{11}^{B}$ is about $0.5 \%$. Then, for the $S 4$ level, the good correlation between EBSD map, DIC measurements and FEM results show that taking into account the crystallographic texture is sufficient to represent the mechanical behavior of the weld nugget. In the middle of the plate (from $7.8 \mathrm{~mm}$ below the top surface of the weld nugget), crystallographic orientations variation is mainly responsible for strain heterogeneities.

\section{Concluding remarks}

The mechanical behavior of the 2050 FSW weld nugget was characterized in the weld direction and at different distances to the weld surface. The periodic variation of crystallographic features on $L T-S T$ surfaces of the tensile specimens forms bands of two types. These bands correspond to the sections of the FSW induced "onions rings" and lead to some uncommon strain response of the material. It was experimentally shown by in situ optic microscopy during tensile tests and digital image correlation that the type A bands undergo more deformation than the type B bands. Some general trends were quantitatively observed on the gap in the strain response between these two types of bands, and 
a

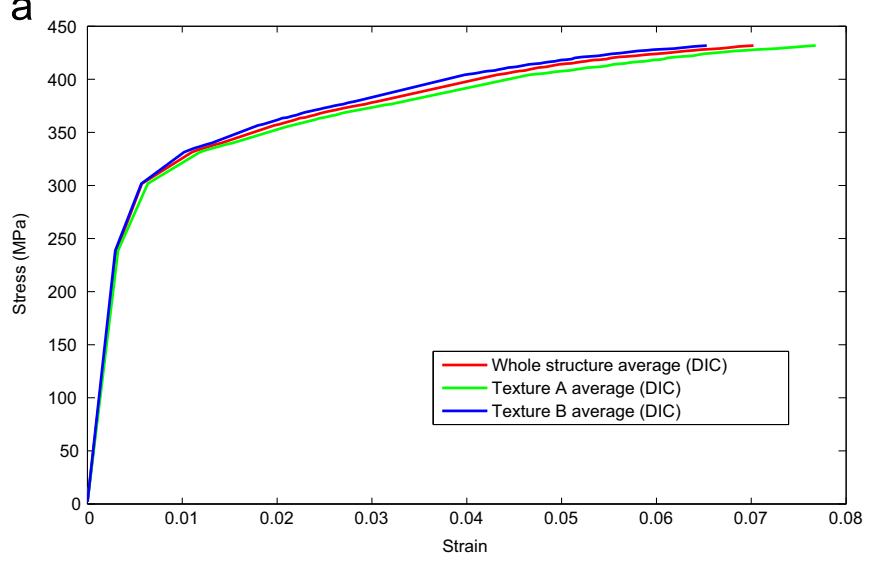

b

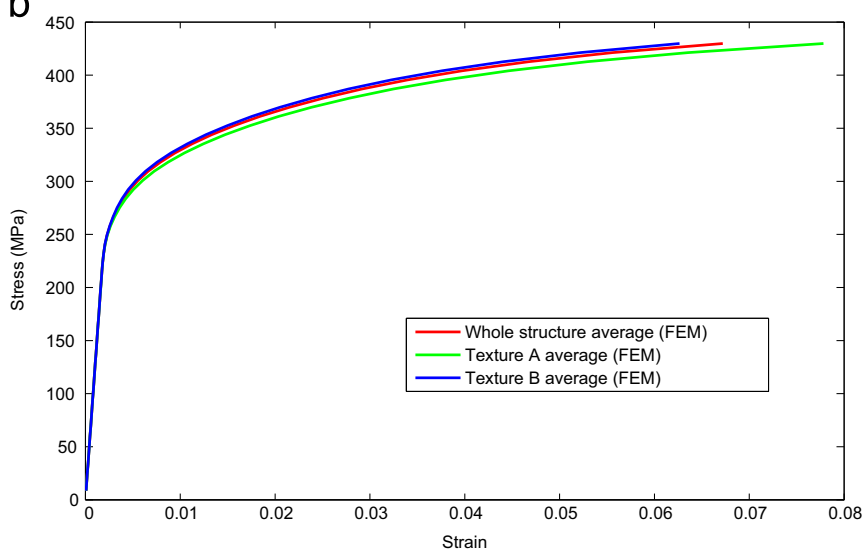

C

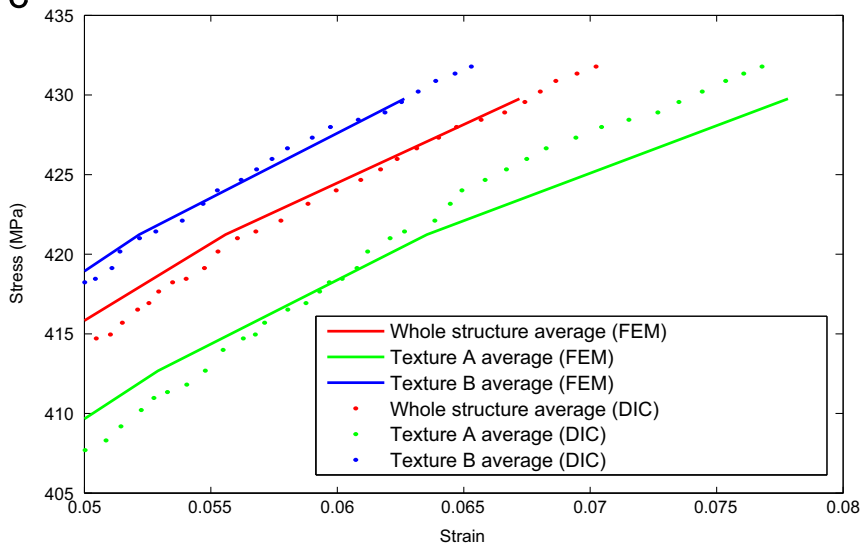

Fig. 8. Tensile tests curves obtained by (a) DIC method, and by (b) finite element method. Red, green and blue curves represent the average stress as a function of the average strain on the whole aggregate, on the A bands, and on the B bands, respectively. (For interpretation of the references to color in this figure caption, the reader is referred to the web version of this paper.)

on the change of this gap with the distance to the upper surface of the weld. Crystal plasticity computations on a volume of material containing few textured bands simulate well the heterogeneity of the strain field. The mechanical behavior of each textured band was calculated. The strain gradient at the interface between the different types of bands is obviously produced probably some deleterious mechanical conditions favorable for example to the initiation and propagation of stress corrosion cracking [17]. The proposed mechanical analysis of the nugget of the weld is then very useful for estimating possible damage initiation and propagation and more generally for assessing the durability of the welds by friction stir welding.

\section{Acknowledgments}

This work was financially supported by the ANR MatetPro program ANR-08-MAPR-0020-05 (Coralis project, Corrosion of Aluminium Lithium Structures).

\section{Appendix. Supporting information}

Supplementary data associated with this article can be found in the online version at http://dx.doi.org/10.1016/j.msea.2015.05.072.

\section{References}

[1] P. Lequeu, K. Smith, A. Danielou, Aluminum-copper-lithium alloy 2050 developed for medium to thick plate, J. Mater. Eng. Perform. 19 (6) (2010) $841-847$.

[2] P. Threadgill, A. Leonard, H. Shercliff, P. Withers, Friction stir welding of aluminium alloys, Int. Mater. Rev. 54 (2) (2009) 49-93.

[3] D. Lohwasser, Z. Chen, Friction Stir Welding: from Basics to Applications, Woodhead Publishing Series in Welding and Other Joining Technologies, Elsevier, UK, 2009, 436 pp.

[4] K. Jata, S. Semiatin, Continuous dynamic recrystallization during friction stir welding of high strength aluminum alloys, Scr. Mater. 43 (8) (2000) 743-749.

[5] A. Steuwer, M. Dumont, J. Altenkirch, S. Birosca, A. Deschamps, P. Prangnell, P. Withers, A combined approach to microstructure mapping of an Al-Li AA2199 friction stir weld, Acta Mater. 59 (8) (2011) 3002-3011.

[6] M. Jones, P. Heurtier, C. Desrayaud, F. Montheillet, D. Allehaux, J. Driver, Correlation between microstructure and microhardness in a friction stir welded 2024 aluminium alloy, Scr. Mater. 52 (8) (2005) 693-697.

[7] A. Simar, Y. Bréchet, B. deMeester, A. Denquin, C. Gallais, T. Pardoen, Integrated modeling of friction stir welding of 6xxx series Al alloys: process, microstructure and properties, Prog. Mater. Sci. 57 (1) (2012) 95-183.

[8] G. Pouget, A. Reynolds, Residual stress and microstructure effects on fatigue crack growth in AA2050 friction stir welds, Int. J. Fatigue 30 (3) (2008) 463-472.

[9] P. Cavaliere, M. Cabibbo, F. Panella, A. Squillace, 2198 Al-Li plates joined by friction stir welding: mechanical and microstructural behavior, Mater. Des. 30 (9) (2009) 3622-3631.

[10] E. Bousquet, A. Poulon-Quintin, M. Puiggali, O. Devos, M. Touzet, Relationship between microstructure, microhardness and corrosion sensitivity of an AA2024-T3 friction stir welded joint, Corros. Sci. 53 (9) (2011) 3026-3034.

[11] E. Bousquet, A. Poulon-Quintin, O. Devos, M. Puiggali, M. Touzet, Microstructure, mechanical and corrosion behaviour of an AA2024-T3 FSW joint, Adv. Mater. Res. 409 (2012) 257-262.

[12] V. Proton, J. Alexis, E. Andrieu, C. Blanc, J. Delfosse, L. Lacroix, G. Odemer, Influence of post-welding heat treatment on the corrosion behavior of a 2050T3 aluminum-copper-lithium alloy friction stir welding joint, J. Electrochem. Soc. 158 (5) (2011) C139-C147.

[13] M. Sutton, B. Yang, A. Reynolds, R. Taylor, Microstructural studies of friction stir welds in 2024-T3 aluminum, Mater. Sci. Eng. A 323 (1-2) (2002) 160-166.

[14] B. Yang, J. Yan, M. Sutton, A. Reynolds, Banded microstructure in AA2024-T351 and AA2524-T351 aluminum friction stir welds. Part I. Metallurgical studies, Mater. Sci. Eng. A 364 (1-2) (2004) 55-65.

[15] R. Fonda, J. Bingert, Texture variations in an aluminum friction stir weld, Scr. Mater. 57 (11) (2007) 1052-1055.

[16] V. xProton, J. Alexis, E. Andrieu, J. Delfosse, M.-C. Lafont, C. Blanc, Characterisation and understanding of the corrosion behaviour of the nugget in a 2050 aluminium alloy friction stir welding joint, Corros. Sci. 73 (2013) 130-142.

[17] M. Dhondt, I. Aubert, N. Saintier, J.M. Olive, Effects of microstructure and local mechanical fields on intergranular stress corrosion cracking of a friction stir welded aluminum-copper-lithium 2050 nugget, Corros. Sci. 86 (2014) $123-130$.

[18] F. DeGeuser, B. Malard, A. Deschamps, Microstructure mapping of a friction stir welded AA2050 Al-Li-Cu in the T8 state, Philos. Mag. 94 (13) (2014) $1451-1462$.

[19] ZeBuLoN, 〈www.zset-software.com/products/zebulon/〉.

[20] G. Cailletaud, S. Forest, D. Jeulin, F. Feyel, I. Galliet, V. Mounoury, S. Quilici, Some elements of microstructural mechanics, Comput. Mater. Sci. 27 (3) (2003) 351-374.

[21] K. Hassan, A. Norman, D. Price, P. Prangnell, Stability of nugget zone grain structures in high strength Al-alloy friction stir welds during solution treatment, Acta Mater. 51 (7) (2003) 1923-1936. 